ISSN 2179-345X

Licenciado sob uma Licença Creative Commons

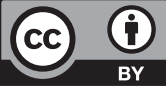

\title{
La responsabilidad social corporativa: una reflexión
}

\author{
A responsabilidade social corporativa: uma reflexão
}

\author{
Rosario Valpuesta Fernández
}

Catedrática de Derecho Civil, Universidad Pablo de Olavide, Sevilla - España, e-mail: rvalfer@upo.es

\section{Resumen}

Reflexión sobre la actividad de las empresas en relación al que es conocido como responsabilidad social corporativa. Reflexión en un nivel técnico jurídico, que lleva a abordar el concepto y significado de la empresa en el mundo del Derecho. Responsabilidad social implica el compromiso voluntario de conducta adecuado para derechos humanos o la defensa de la propiedad que son socialmente asumidos por las empresas incrustadas en sus cánones de actividad. Las dificultades de la aplicación de la responsabilidad social corporativa en áreas donde hay una mayor flaqueza institucional para tutear en el mercado, a nivel regional, dada la dimensión económica, en los procesos de integración, y en la escena internacional, cuando falta de mecanismos o instrumentos para intervenir en la actividad empresarial.

Palabras-clave: Responsabilidad social corporativa. Derechos humanos. Actividad empresarial. 


\section{Resumo}

Este texto faz uma reflexão sobre a atividade das empresas em relação ao que é conhecido como responsabilidade social corporativa. Reflexão essa em um nível técnico jurídico, que leva a abordar o conceito e o significado da empresa no mundo do Direito. Responsabilidade Social implica o compromisso voluntário de conduta adequado para os direitos humanos ou a defesa da propriedade, o que é socialmente assumido pelas empresas e incorporado em seus cânones de atividade. É preciso averiguar as dificuldades da aplicação da responsabilidade social corporativa em áreas onde há uma maior fraqueza institucional para atuar no mercado, a nível regional, dada a dimensão econômica, nos processos de integração e na cena internacional, quando faltam mecanismos ou instrumentos para intervir na atividade empresarial.

Palavras-chave: Responsabilidade social coorporativa. Direitos humanos. Atividade empresarial.

\section{Introducción}

En estas páginas se quiere aportar una reflexión sobre la actividad de las empresas en relación a lo que se conoce como la responsabilidad social corporativa (RSC). Y esta reflexión nos pretende desenvolverse en un plano técnico jurídico, que lleve a abordar el concepto y significado de la empresa en el mundo del Derecho; una tarea que a buen seguro requeriría de un especial detenimiento por cuanto nos enfrentamos a una noción sobre la que aún no se han puesto de acuerdo los juristas, y en la que confluyen posiciones ideológicas y doctrinales muy diferentes y que tienen que ver, sin duda, con la función que las empresas han de desempeñar en el Estado Democrático y Social (FONT GALÁN, 2007, p. 59-64).

En esta línea, tampoco se procura dilucidar acerca de las diferentes formas empresariales desde una perspectiva jurídica, es decir, acercarnos a las nuevas vestes con las que se invisten las empresas para el ejercicio de su actividad y su protagonismo en las relaciones de intercambio. 
Ello nos exigiría considerar aquellas manifestaciones que pueden suscitar alguna duda acerca de su verdadera naturaleza; nos referimos más en concreto a la virtualidad de las fundaciones, que separándose de lo que ha sido su función tradicional en el Derecho de inspiración francesa, asumen ahora una actividad típicamente económica o, si se quiere, empresarial (CARRANCHO HERRERO, 1991).

Tampoco se quiere entrar a valorar los tipos de lucros que pueden generar las empresas, tengan éstos una dimensión societaria, mutualista o cooperativa. Pues si bien su categorización nos permitirá evaluar el alcance que los beneficios empresariales tienen para sus protagonistas, en este momento consideramos todos y cada uno de ellos como señas de identidad de la empresa.

Se utiliza pues el concepto de empresas en un sentido material, para referimos a los actores económicos presentes en la producción de bienes y servicios y sus intercambios; o si se quiere, desde una perspectiva económica, a la organización de capital y trabajo destinada a la intermediación de bienes y servicios para el mercado con el fin de generar ganancias. Unos actores económicos que con independencia de la veste con la que se presenten tienen como objetivo maximalizar los beneficios en el ejercicio de su actividad. Hablamos pues de actores económicos que adquieren una subjetividad jurídica para poder actuar en el mercado a fin de defender y preservar sus intereses, de naturaleza eminentemente privados.

Ellos son los que se arrogan el protagonismo en la economía de mercado, son ellos los que pretenden definir un sistema económico que pivota en torno a la iniciativa privada para la producción y comercialización de los bienes. Y su seña de identidad es la libertad económica, que se nos quiere presentar como la panacea para la construcción de la democracia; de tal manera, se nos dice, sin esta libertad no hay democracia. Con ello se resalta o se pone de manifiesto las implicaciones que tienen en el tema que abordamos, las cuestiones referidas a la construcción política del gobierno que se quiere, y su representatividad del conjunto de la ciudadanía. 
Y en esta línea, de un tiempo a esta parte ha surgido en el debate político y económico la responsabilidad social de las empresas. En una primera aproximación se podría entender por tal el compromiso de aquéllas con los valores colectivos definidos por la sociedad. Significa que tales empresas asumen que son parte de la comunidad y en consecuencia tienen que orientar su actividad económica a la realización de fines definidos por la misma, de tal modo que su gestión debe responder a los objetivos sociales identificados políticamente. Incluso, se habla de la función social de las empresas, parafraseando a la propiedad, para insistir aún más en la perspectiva social de su contenido, y en la necesidad de que la actividad económica que desarrollan responda a una más justa distribución de la riqueza así como con la defensa de bienes que todos pertenecen, como el medio ambiente.

Cosa distinta es lo que se conoce más específicamente como responsabilidad social corporativa (RSC), pues con ello se hace referencia a algo más concreto que tiene que ver con los programas voluntarios desarrollados por algunas empresas en los que se comprometen con la defensa de determinados valores, que incorporan a su actividad económica. Responden pues a la idea de evidenciar su implicación con tales valores adoptando políticas y prácticas empresariales en los ámbitos económico, social y medioambiental. Su concreción responde a las presiones de determinados grupos de interés, que se conocen como los stakeholders, para que las empresas se acomoden a ciertas exigencias éticas (CUESTA GONZALEZ, 2004) ${ }^{1}$.

De la constatación de esta realidad surge la propuesta de lo que se conoce como responsabilidad social corporativa que, como hemos dicho, implica el compromiso voluntario por parte de las empresas de incorporar a su actividad cánones de conducta más adecuados a los derechos

1 El enfoque de la voluntariedad o business case argumenta a favor de la responsabilidad social corporativa (RSC), en función del beneficio que esta estrategia puede suponer para el negocio, para la empresa. De ahí que se denomine el "business case for corporate social responsibility". Fundamentalmente, este enfoque se basa en los vínculos existentes o potenciales entre la calidad de las relaciones de la empresa con sus stakeholders y sus resultados económicos.

Revista de Direito Econômico e Socioambiental, Curitiba, v. 3, n. 1, p. 169-202, jan./jun. 2012 
humanos o la defensa de bienes que son asumidos socialmente (EMBID IRUJO, 2004).

\section{La responsabilidad social corporativa: una aproximación}

Su origen se ha situado en la cultura anglosajona, y responde en un primer momento a un intento de moralización de la actividad económica, de comprometerla con valores ajenos a la empresa. Entonces no se trataba de interferir en su organización ni de imponerle criterios en lo que concierne a su actividad interna, solo de fijar unos límites externos referidos a la comercialización de determinados productos cuyo consumo era rechazado por algunos colectivos, nos referimos en concreto al alcohol, al tabaco, o a las armas. En otro nivel las exigencias a las empresas se concretaron en la reprobación de determinadas prácticas como la segregación racial existente en Sudáfrica, vetando por ello el comercio con este país. De estas primeras manifestaciones por las que algunos colectivos quisieron imponer sus creencias a la actividad de las empresas, se ha pasado a una cierta institucionalización de lo que se conoce como la responsabilidad social corporativa ${ }^{2}$.

2 También se ha señalado como origen: después de la Conferencia de Baudung (1955), en la que el movimiento de los no alineados emergió, estos países del Tercer Mundo hicieron demandas precisas en relación con un nuevo orden internacional y económico. Propusieron reformas estructurales en el orden de comercio mundial, en comunicaciones, en el acceso a nuevas tecnologías... y, en el primer caso, un control público de las empresas multinacionales. Estas demandas se hicieron muy populares en los años 60s: se iniciaron negociaciones entre los países industrializados y los del Tercer Mundo, bajo los auspicios de la CNUCD. La Asamblea General de Naciones Unidas decidió crear una comisión de Multinacionales así como un centro de investigación sobre sus actividades. El propósito fue ciertamente desarrollar un instrumento universal para sujetar a las multinacionales a reglas públicas. La Cámara Internacional de Comercio encendió la mecha en 1972 con su "Guía para Inversiones Internacionales". La Cámara argumenta: sobre las grandes ventajas de la inversión internacional. Sobre la necesidad de la consulta entre países anfitriones y empresas para facilitar el entendimiento. Sobre la obligación de tratar a las empresas multinacionales como nacionales. Sobre los efectos desastrosos de un código obligatorio, el cual sería un obstáculo a la inversión internacional. 
Esta se fundamenta en una constatación: la influencia que en los stakeholders tiene el comportamiento de las empresas en relación a determinados valores, y que pueden influir en su rentabilidad económica. Se entiende por stakeholders todas aquellas personas, colectivos o entidades de las que dependen las empresas para alcanzar sus objetivos; entre ellos están los trabajadores, los consumidores, las comunidades en las que ubican, también las ONGs, como creadoras de opinión, así como los medios de comunicación por su capacidad de difundir informaciones y valoraciones sobre la actividad económica de las mismas ${ }^{3}$ (CUESTA GONZALEZ, 2004, p. 47).

Desde esta perspectiva, frente a la idea tradicional de que las empresas se deben a sus accionistas, se contrapone esta otra que coloca a los operadores antes mencionados, los stakeholders, como los destinatarios de la actividad empresarial, en la medida que con su comportamiento pueden determinar el éxito de una iniciativa económica. Es decir, es la rentabilidad de las empresas la que impulsa su compromiso con los valores dominantes, a través de lo que se conoce como responsabilidad social corporativa

Los países industriales pronto se convencieron de estos principios, y las negociaciones comenzaron poco a poco a fracasar. La Comisión de la ONU sobre Multinacionales fue hecha a un lado, y las reformas estructurales fueron abandonadas. Estos años 60s se volvieron de suma importancia, conforme las autoridades públicas nacionales e internacionales se desarmaron, bajo presión de los círculos empresariales, y renunciaron al establecimiento de reglas públicas que gobernaran las actividades económicas, monetarias y comerciales, cuya dimensión, de cualquier manera, se volvió crecientemente global. De cara a la demanda de medidas por parte de una opinión pública particularmente sindicalista, la respuesta llegó en 1976 con los Códigos de Conducta sobre Inversiones Internacionales y Multinacionales y en 1977 con la Declaración Tripartita de Principios Sobre Empresas Multinacionales y la Política Social, /Gérard FONTENEAU, LAGJS/LISDINYS ENSAYO/ Responsabilidad Social Corporativa (E002) OCTUBRE03.

3 Se trata de individuos o grupos de individuos que bien por motivos religiosos, éticos, o sociales desean como consumidores, inversores y gestores que todas sus actuaciones y decisiones se impregnen de esos valores y reclaman un comportamiento responsable de la empresa con los empleados con sus productos, con sus procesos y con sus clientes. A ellas, como al resto de organizaciones, privadas o públicas, con o sin ánimo de lucro, les exigen las mismas responsabilidades sociales y medioambientales que se exigirían a cualquier individuo. Son pues ciudadanos convencidos o activistas que abogan por un modelo económico y social donde prime el interés colectivo sobre el individual.

Revista de Direito Econômico e Socioambiental, Curitiba, v. 3, n. 1, p. 169-202, jan./jun. 2012 
(BIGNÉ, 2005, p. 16) . Y así, a los tradicionales parámetros que valoran la eficiencia económica de las mismas, que se miden en términos de maximización y productividad, se le suma la "eficiencia social" (CUERVO, 2005), que coloca a la reputación como una ventaja competitiva de las empresas (FUENTES GANZO, 2006, p. 15). Tiene su fundamento último en la ética, que también debe aplicarse a aquéllas (CORTÉS GARCÍA, 2008, p. 40). $Y$ así se dice que la implantación de la RSC en la empresa en un marco ético, debe abordar sistemática, coherente y simultáneamente todos los pilares que la definen: el buen gobierno corporativo, la acción social, la inversión socialmente responsable y el modelo de gestión (CORTÉS GARCÍA, 2008, p. 45).

Este compromiso de responsabilidad social se opera sin la intermediación de los Estados, se activa por la presión que diferentes grupos de interés, y en la medida que tengan capacidad para influir en el comportamiento de las empresas, lo que ocurre cuando contribuyen a la mejora de su propia rentabilidad.

Dicha responsabilidad no se concreta en la constitución de fondos de ayuda a proyectos de alcance humanitario, aunque se puede manifestar de esta forma. Se realiza mediante la implementación de prácticas, estrategias y objetivos que contribuyan a un desarrollo sostenible y de respeto del medio ambiente, así como a la realización de los DDHH y de otras exigencias sociales, como la lucha contra la corrupción. Todo ello orientado a la finalidad implícita de integrar a las empresas en la sociedad civil, con la intención de que jueguen un papel más activo en la conformación de la misma (FONTENEAU, 2003) ${ }^{5}$.

4 Tradicionalmente, en la dirección de marketing se han evaluado los resultados en términos de ventas, cuota de mercado y satisfacción. Estos indicadores poseen un claro interés para gestores y accionistas (enfoque shareholder). Sin embargo, en la actualidad, está adquiriendo mayor peso una perspectiva más amplia, que incorpora las prioridades de otros agentes o grupos de interés con los que se relaciona la organización (enfoque stakeholder).

5 Como pone de manifiesto, Gérard Fonteneau, el concepto acoge a gran variedad de logros e iniciativas: inquietudes morales y éticas, "buena gobernanza" en forma de códigos de conducta, "estatutos" autoproclamados, etiquetas sociales, inversiones éticas, inversiones "socialmente responsables", etiquetas sociales dependientes de Bélgica o Dinamarca o de alguna ley; en todo caso, el autor propone una clasificación: Códigos de Conducta, Estatutos y Declaraciones autoproclamadas.

Revista de Direito Econômico e Socioambiental, Curitiba, v. 3, n. 1, p. 169-202, jan./jun. 2012 
Este compromiso de las empresas tiene carácter voluntario, como hemos dicho, no se corresponde con el cumplimiento de las prescripciones legales impuestas por el poder político, pues su carácter vinculante impide cualquier tipo de disposición por parte de las mismas. Viene en consecuencia a cubrir las carencias de las instituciones para imponer a la iniciativa privada objetivos sociales y medioambientales. La RSC responde a una decisión empresarial de compromiso más allá de las exigencias normativas, y tiene que ver con la influencia que en su actividad pueden tener los distintos operadores (BIGNÉ, 2005) ${ }^{6}$.

Por ello surge en el escenario internacional, donde la falta de control de las empresas es evidente, y la necesidad de su adecuación a los valores universalmente asumidos una exigencia. Se inicia con el Pacto Mundial (The Global Compact) en el seno de NNUU, que se elabora durante la Secretaría General de Kofi Annan (año 2000), con la intención de promover el desarrollo sostenible y la responsabilidad social de las empresas, involucrando para ello a las más representativas en el contexto internacional. Como se ha dicho, no tiene carácter vinculante, pues su cumplimiento se deja a la iniciativa de estos actores económicos (FUENTES GANZO, 2006, p. 16) ${ }^{7}$.

Para la elaboración de los códigos de conductas a los que se deben adecuar las empresas que suscriban tal Pacto, se tiene en cuenta la Declaración Universal de los Derechos Humanos, los Acuerdos de la Organización Internacional del Trabajo, la Declaración de Río sobre el Medio Ambiente y el Desarrollo y la Convención de las Naciones Unidas contra la Corrupción. Aunque también hay que señalar que se toman en cuenta otros Tratados internacionales sobre DDHH como el Pacto

6 Faltan aún estudios completos sobre la incidencia que la RSC tiene en los stakeholders, una muestra de los mismos dirigidos a consumidores en Enrique Bigné: para tales objetivos se diseñó un estudio cross-cultural en Argentina, Chile, España y Portugal. La investigación se dirigió a estudiantes universitarios durante el periodo abril-junio de 2003. La elección de este segmento de jóvenes consumidores obedece a un doble criterio. De un lado, son los futuros dirigentes sociales y empresariales y, por tanto, puede proporcionar indicios de su futuro comportamiento. De otro, son consumidores de productos seleccionados en el estudio (zapatillas y desodorante).

7204 empresas españolas se han adherido al Pacto.

Revista de Direito Econômico e Socioambiental, Curitiba, v. 3, n. 1, p. 169-202, jan./jun. 2012 
Internacional sobre los Derechos Económicos Sociales u Culturales, de 1966. En definitiva, estamos hablando de instrumentos internacionales de cumplimiento obligatorio cuando son ratificados pos los Estados, de tal forma que integran el Ordenamiento Jurídico de cada país; unos instrumentos internacionales a los que las empresas multinacionales escapan, precisamente por su dimensión internacional, de ahí que se plantee en este ámbito la necesidad de de adecuar su actividad a estas exigencias. Con estas referencias se formulan diez principios que han de guiar la actividad empresarial de las entidades que se adhieran. Estos son:

1) las empresas deben apoyar y respetar la protección de los derechos humanos proclamados en el ámbito internacional;

2) las empresas deben asegurarse de no ser cómplices en abusos a los derechos humanos;

3) las empresas deben respetar la libertad de asociación y el reconocimiento efectivo del derecho a la negociación colectiva;

4) las empresas deben eliminar todas las formas de trabajo forzoso u obligatorio;

5) las empresas deben abolir de forma efectiva el trabajo infantil;

6) las empresas deben eliminar la discriminación con respecto al empleo y la ocupación;

7) las empresas deben apoyar los métodos preventivos con respecto a problemas ambientales;

8) las empresas deben adoptar iniciativas para promover una mayor responsabilidad ambiental;

9) las empresas deben fomentar el desarrollo y la difusión de tecnologías inofensivas para el medio ambiente;

10) las empresas deben trabajar contra la corrupción en todas sus formas, incluyendo la extorsión y el soborno.

Como se puede comprobar los principios referidos representan la expresión mínima de unos derechos que en su aplicación tienen 
múltiples posibilidades y que se ignoran en el Pacto. Se trata pues de un compromiso de mínimos.

Este Pacto Mundial, se refuerza con una cierta institucionalidad que se concreta en la creación de una Oficina del Pacto con sede en New York, a cuyo frente hay Chief Executive, y en su organigrama se integran el Alto Comisionado de NNU para los DDHH, la OIT, y los programas de Desarrollo y Medio Ambiente de NNUU.

Antes incluso de esta iniciativa habían surgido otras de naturaleza privada con la finalidad de elaborar estándares de comportamiento que sirvieran de guía a las empresas para implementación de prácticas ligadas a determinados objetivos ligados al los DDHH o a la protección del ambiente, sin embargo es después del Pacto Global cuando se toma conciencia de la responsabilidad social corporativa y proliferan las iniciativas en este sentido.

En concreto, nos referimos a The Global Reporting Initiative (GRI), constituido en 1997 por el impulso conjunto de dos organizaciones no gubernamentales, Coalition for Environmentally Responsible Economies (Cebes) y Programa de las Naciones Unidas para el Medio Ambiente (PNUMA). Su objetivo es aumentar la calidad, el rigor y la utilidad de las memorias de sostenibilidad. A su desarrollo han contribuido representantes de empresas, organizaciones asesoras no lucrativas, sindicatos, empresas auditoras... Su propuesta se ha concretado en la Guía para la Elaboración de Informes de Sostenibilidad, cuya primera edición es del año 2000, y cuenta con una nueva versión del año 2002. En la noción de sostenibilidad incluye también otros aspectos de índole económica, así como sociales y medio ambientales. Se trata pues de guiar a las empresas para que den cuenta de su compromiso con un crecimiento equilibrado y sustentable.

Otra iniciativa en este sentido corresponde a Social Accountability Internacional (SAI), organización no gubernamental en materia de derechos humanos, que ha elaborado una de las normas estándar más universalmente aceptada, la SA 8000, que ofrece la posibilidad de verificar el cumplimiento de las normas de DDHH, de la OIT, y diversas Convenciones de derechos. La Social Accountability 8000 (SA 8000) es una norma internacional para la responsabilidad social iniciada por 
Consejo de la Agencia para la Prioridad Económica (Cepaa) a fin de definir criterios para la producción ética de bienes y servicios.

Como todas, tiene carácter voluntario y está diseñada para poder aplicarse a cualquier organización o empresa en el campo industrial. En concreto, toma en consideración determinadas prácticas que vulneran los derechos humanos, y a las que las empresas se comprometen a erradicar en su ámbito de actuación; más específicamente se refiere al trabajo infantil, el trabajo forzado, a la salud y la seguridad, a la libertad de asociación y al derecho de intercambio colectivo, a los comportamientos discriminatorios, a las prácticas disciplinarias, a las horas de trabajo y las compensaciones. Como se puede comprobar, de nuevo estamos ante un compromiso de mínimos, que debería ser exigido a todas las empresas sin necesidad de recurrir a la responsabilidad social corporativa.

Sus exigencias en las materias expuestas se fundamentan en las recomendaciones de la Organización Internacional del Trabajo, en la Declaración Universal de los Derechos Humanos de las Naciones Unidas (NU), en la Convención de los Derechos del Niño de las Naciones Unidas y otras Convenciones. Para su efectividad se requiere, además de unas reglas de funcionamiento, un Sistema de Gestión Social (Social Management System - SMS) con el fin de asegurar el acatamiento de las normas así como la permanencia de las prácticas referidas ${ }^{8}$. Su implementación requiere de un sistema de gestión que contemple una política social, un proceso de planificación y la designación de un director con experiencia para asegurar el cumplimiento de las normas de SA 8000. Bajo estos auspicios se han constituidos organizaciones que integran a empresas que se quieren adherir a estas prácticas.

World Bussines Council for Sustanaible Development (WBCSD) es una coalición de 200 empresas internacionales con un objetivo común: el desarrollo sostenible ha de alcanzarse a través del crecimiento económico, el equilibrio ambiental y el progreso social. Mediante esta alianza las empresas en la consecución de los objetivos propuestos se impulsan

8 El SMS de SA 8000 está basado en el sistema de gestión ISO 9000/14000.

Revista de Direito Econômico e Socioambiental, Curitiba, v. 3, n. 1, p. 169-202, jan./jun. 2012 
el intercambio mutuo de conocimientos y prácticas, en particular, entre las organizaciones asociadas en los países con similares características socioeconómicas y culturales y que, a menudo, comparten retos comunes. En este sentido, el acceso a los programas del WBCSD permite la trasmisión de experiencias, herramientas y material de construcción de capacidad para la implementación de los objetivos propuestos. Así mismo, se facilita la comunicación con los principales actores internacionales y plataformas que trabajan por los negocios y el desarrollo sostenible, al mismo tiempo que se establecen contactos y vínculos con las corporaciones globales, fomentando al aprendizaje entre países y sectores (FUNDACIÓN ENTORNO-BCSD ESPAÑA, 2012).

Por aportar algunos datos que nos permitan apreciar la dimensión de WBCSD, su capitalización en el mercado es U.S. \$ 5.400 billones; cuentan con 12 millones de empleados, sus productos y servicios se distribuyen a 3.000 millones de consumidores cada día; se ha organizado en 55 Consejos Regionales en Europa, Asia, Norteamérica, Latinoamérica y Oceanía (FUNDACIÓN ENTORNO-BCSD ESPAÑA, 2012). Estos datos avalan su capacidad de influir en las agendas públicas y privadas del Desarrollo Sostenible.

Por su parte, la OCDE ha asumido también este objetivo de las empresas, y lo ha recogido en Líneas Directrices para Empresas Multinacionales de la OCDE, que se concretan en 11 propuestas, que en gran medida recogen los principios del Pacto Global, con una adición, la prohibición de injerencia en las actividades políticas locales.

A nivel europeo, la recepción de este fenómeno se opera en el Libro Verde sobre el marco europeo de la responsabilidad social corporativa, cuya iniciativa se adopta en la Cumbre de Lisboa del año 2000 y su realización culmina el año 2001 (FONTENEAU, 2003).

9 En este asunto, la Comisión no tiene legitimidad legal alguna. El Tratado reconoce dos instrumentos normales: la legislación europea (directrices sociales) y acuerdos, como el Tratado de Ámsterdam que instituyó el papel co-regulador de ambos lados de la industria (patronos y trabajadores). En estas circunstancias, la Comisión no debe respaldar el papel regulador parcial de los patronos solamente. Esta situación también revela el alto nivel de penetración de la ideología neoliberal en las instituciones europeas y entre muchos funcionarios.

Revista de Direito Econômico e Socioambiental, Curitiba, v. 3, n. 1, p. 169-202, jan./jun. 2012 
En este ámbito, a igual de lo ocurrido a nivel internacional, han surgido organizaciones de empresas como Corporate Social Responsability (CSR), para la elaboración de estándares de Balance Social, incorporando los ya realizados por otras organizaciones como la WBCSD o la SAI.

En este sentido, la información sobre las actuaciones socialmente responsables requiere una normalización que tiene que partir, en primer lugar, del consenso de los grupos de interés acerca de la información a suministrar y, en segundo lugar, de una legislación que regule la presentación de la misma. En este punto la contabilidad desempeña un importante papel como mecanismo de información tradicional y generalmente aceptado (MENDEZ PICAZO, 2003, p. 147).

El reto que para las empresas y para la sociedad en general implica el desarrollo de la responsabilidad social corporativa en línea de principios se puede considerar un avance importante en el desenvolvimiento de de la economía de mercado. Sin embargo, si reparamos más detenidamente en su alcance y significado, las conclusiones deben ser otras.

\section{La pretendida dialéctica entre el mercado y el Derecho}

El tema propuesto nos lleva a un escenario más amplio, aquél en el que los actores son, por un lado, las empresas, entendidas como agentes económicos del capitalismo y, de otro lado, el Estado, como defensor de los intereses generales. Una dialéctica que se ha querido presentar como la expresión de una relación más amplia, la que se da entre el mercado y el Derecho, es decir entre la actividad productiva y de tráfico de bienes y servicios y el poder regulatorio del Ordenamiento jurídico.

Pero esta relación tal como se nos muestra puede esconder una trampa ideológica que conviene desenmascarar: la de entender que el mercado es un espacio separado del Derecho, que se desenvuelve a impulsos 
propios y con capacidad de generar sus propias reglas ${ }^{10}$, muy en la línea de lo que IRTI ${ }^{11}$ ha identificado como la orientación naturista en el enfoque y tratamiento de las relaciones entre mercado y Derecho. Desde esta perspectiva, se pretende sustituir el discurso político que necesariamente sustenta la regulación del tráfico de bienes y servicios por una explicación economicista del mismo, en el sentido de que los principios que lo rigen, las soluciones que se aportan o las estrategias que se diseñan responden a la lógica interna de las relaciones de intercambio, a la que deben ser ajenas la política y el Derecho. Se dice, en consecuencia, que las reglas del juego que han de regir el mercado no son externas al sistema, sino que surgen de él como un precipitado de los intereses que lo presiden. Desde estos postulados se propugna lo que se ha dado en llamar la desregulación de las relaciones de mercado, para que sea éste el que fije sus objetivos y medios para conseguirlo ${ }^{12}$.

10 Como afirma Paz-Ares (1981, p. 610), "Si el Derecho privado expresa la misma lógica que el mercado, su fundación debe ser la norma de eficiencia, el cumplimiento de cuyos dictados, a su vez - y el argumento es circular- solo resulta viable mediante una organización que asegure que en todo caso será la decisión del mercado la llamada a prevalecer".

11 "Esta solución, que proviene de la aceptación de las leyes de la naturaleza y que describe por tanto la uniformidad que se encuentra frente a nosotros, es verdadera e incontrovertible" (BALAGUER CALLEJON, F. Derecho y mercado. Revista de Derecho Patrimonial, n. 3, 1999, p. 22). "Para la desarticulación del Estado social se ha buscado una metodología más eficaz: la ciencia económica, que recupera los propios términos deterministas del raciocinio exponiendo como verdades absolutas e inevitables los postulados del modelo económico vigente e incluso de una determinada política económica", "El Estado social y democrático de Derecho. Significado, alcance y vinculación de la cláusula del Estado social" (PEREZ, J. L. M.; NAVARRETE, C.; VIDA, M. N. M. (Ed.). Comentario a la Constitución Socio-económica de España. Granada: Comares, 2002. p. 90).

12 Como continúa IRTI, el mercado no extrae de sí mismo su propio Derecho, sino que el Derecho desde el exterior lo constituye y lo conforma, y el contenido de las normas procede de una elección política, y por tanto la fisonomía jurídica del mercado está trazada por una decisión de poder, "Derecho y mercado" cit. pg. 25. En esta línea, Garcia-Pelayo (2000, p. 59) afirma que "El Estado no puede limitarse a asegurar las condiciones ambientales de un supuesto orden social inmanente, ni a vigilar los disturbios de un mecanismo autorregulado, sino, por el contrario, ha de ser el regulador decisivo del sistema social y ha de disponerse a la tarea de estructurar la sociedad a través de medidas directas o indirectas" (GARCIA-PELAYO, M. Las transformaciones del Estado contemporâneo. Madrid: Alianza, 1996, p. 2). Suarez nos recuerda que la experiencia histórica y los dictados de la ciencia económica permiten también sostener que el correcto funcionamiento de un

Revista de Direito Econômico e Socioambiental, Curitiba, v. 3, n. 1, p. 169-202, jan./jun. 2012 
Este planteamiento, muy extendido, no toma en consideración que el mercado necesita del Derecho para su propio funcionamiento, requiere de la fuerza coactiva de las normas y de la institucionalidad que la hace efectiva para poder funcionar. Necesita de las normas laborales para disciplinar las relaciones con los trabajadores, del Derecho privado que le asegure la eficacia de sus derechos, de la publicidad registral que de certeza a las transmisiones inmobiliarias, de las normas societarias que articulen su subjetividad..., es decir, un conjunto de disposiciones que den cobertura a los intereses empresariales al mismo tiempo que los legitimen. Y con certeza necesitan de un poder judicial que le ampare en los conflictos que puedan surgir en la realización de sus intereses.

La cuestión planteada tiene en consecuencia otra dimensión, la de dilucidar si la actuación de las empresas y la normativa que la regula se ha de someter a los principios y valores asumidos por el conjunto de la sociedad o, por el contrario, éstas pueden funcionar al margen de los mismos, en defensa de los intereses individuales que lo impulsan ${ }^{13}$.

En efecto, el Derecho que reclama el mercado es aquél que se ajuste a los intereses privados que lo presiden, que imponga pocas trabas al desenvolvimiento de las empresas en la procura de una maximalización de sus beneficios; un Derecho o, mejor dicho, unas normas jurídicas que en sus objetivos se quieren separar de los principios y valores que el conjunto de la sociedad se ha dotado en el diseño del modelo de convivencia que se quiere. De tal modo que, cabría decir, de un lado está el mercado, con sus propio Derecho, y de otro el Ordenamiento Jurídico que define el proyecto común de los pueblos.

sistema de economía de mercado necesita de mecanismos correctores y poderes compensadores que den respuesta a anhelos colectivos que el mercado por sí solo, debido a sus limitaciones, no puede satisfacer y mantengan las desigualdades económicas que el sistema inexorablemente genera dentro de unos límites socialmente tolerantes, "Progreso económico y justicia social".

${ }^{13}$ La economía, como ciencia social, está relacionada con los principios morales de la sociedad en la que se desarrolla... Por ello podemos decir que la ética, considerada como la ciencia del comportamiento moral, está relacionada con la economía, tanto en sus orígenes como en su desarrollo (MENDEZ, 2003, p. 823). Una exposición sobre el surgimiento de la ética en la empresa y su influencia en la RSC (CORTÉS GARCÍA, 2008, p. 33).

Revista de Direito Econômico e Socioambiental, Curitiba, v. 3, n. 1, p. 169-202, jan./jun. 2012 
Una dialéctica que se da, a juicio de sus defensores, entre posiciones que se desenvuelven en un mismo plano, el de los derechos fundamentales que dan carta de naturaleza a los Estados democráticos, de tal modo que la actividad de las empresas se sustenta en el derecho a la libre iniciativa económica que merece la protección de los poderes públicos, lo mismo que los intereses generales que estos últimos deben realizar. Insistiendo incluso en que el desenvolvimiento de la libertad de empresa responde a su vez a un interés general, por cuanto del mismo depende el desarrollo social y la producción de riqueza. Se debe considerar, en consecuencia, si es posible ubicar en un mismo plano las relaciones de mercado y los intereses generales, de tal modo que ambos se relacionan en un diálogo entre iguales, cuando no funcionan de manera independiente. Una reflexión que requiere tener en cuenta las coordenadas de tiempo y lugar en el que esta dialéctica se produce.

El mercado responde a una experiencia histórica y, como tal, relativa, sujeta a procesos de cambios y transformación que se reflejan en cada momento en el marco jurídico en el que se han de desenvolver las relaciones de producción e intercambio.

Se puede decir, que en el ámbito estatal la disciplina jurídica del mercado forma parte del conjunto del Ordenamiento jurídico, por lo que ha de responder a la coherencia interna que al mismo se le exige, pero sobre todo se ha impregnar de los principios y valores que lo informan, residenciados en el texto constitucional. Como dice Haberle (1997, p. 15), frente a la expansión del economicismo, resulta cada vez más necesaria una teoría constitucional del mercado ${ }^{14}$.

Este planteamiento se ha visto desbordado con el proceso de internacionalización de las empresas, que ha abocado a la globalización financiera y económica que hoy conocemos. En este nuevo escenario la relación entre las empresas y el Estado se difumina por las limitaciones que tienen estos últimos para imponer restricciones, objetivos $\mathrm{y}$

14 "El Estado constitucional coloca al mercado a su servicio, como un sustrato material irrenunciable de sus fines ideales, orientados a favor de la dignidad del hombre y la democracia".

Revista de Direito Econômico e Socioambiental, Curitiba, v. 3, n. 1, p. 169-202, jan./jun. 2012 
estrategias a la actividad de los actores económicos. Ello ha propiciado, sin duda, los procesos de integración regional al objeto de fortalecer el mercado interior y dotarse de instituciones que sirvan de interlocutores a las empresas que operan en ese espacio. Sin embargo, las insuficiencias y las propias limitaciones de los Estados para imponer a las empresas los principios y valores colectivos, se han manifestado igualmente en estos ámbitos regionales en los que son más intensos los intercambios de bienes y servicios, debido a la impronta mercantilista o economicista que tiene su nacimiento.

Una situación que resulta aún más preocupante si se tiene en cuenta que en el ámbito internacional no se cuenta con instituciones con capacidad para imponerse a las empresas trasnacionales, que se desenvuelven con gran libertad sorteando las leyes estatales en un campo yermo de objetivos políticos.

En estos tres espacios debemos reparar para apreciar en todo su significado la responsabilidad social de las empresas.

\section{El ámbito estatal, la experiencia europea}

La teoría constitucional del mercado ha de responder a los postulados del Estado Social en la experiencia más reciente de Europa. Como es sabido, tras el intento de la Constitución de Weimar de 1919 de instaurar un marco jurídico que respondiera a las exigencias de las clases sociales excluidas del poder, el paso del Estado liberal al Estado Democrático y Social se produjo de forma más generalizada en Europa tras la Segunda Guerra Mundial ${ }^{15}$, aunque ya se contaban con experiencias en este sentido (RITTER, 1990, p. 157).

15 Una exposición sobre sus orígenes en Garcia-Pelayo (1996, p. 14), en este sentido afirma: "Las nuevas fuerzas políticas (cristianos sociales, socialistas y comunistas) que afrontaron la reconstrucción y modernización de la Europa de posguerra coincidieron en el mantenimiento de las instituciones clásicas democráticas en lo referente al estatuto de las libertades políticas, si bien rechazaron unánimemente la vuelta a los postulados del liberalismo en el orden económico 
El entendimiento de lo que sea el Estado Social no está exento de dificultades, lo que ha suscitado intensos debates en la doctrina con posiciones muy diferenciadas ${ }^{16}$ que no podemos reflejar en este momento. Sí debemos resaltar, sin embargo, que el advenimiento del Estado Social está unido a la democracia. Su alumbramiento responde a la necesidad de acrecentar la participación efectiva de todas y todos en el destino de la sociedad, lo que solo podría ocurrir si se dotaba a la ciudadanía de las condiciones de igualdad y libertad indispensables para poder actuar de forma autónoma en los distintos espacios de decisión. Y para ello es necesario que se garantice el disfrute de los bienes esenciales mediante el reconocimiento de una serie de derechos sociales, al mismo tiempo que se legitima a los poderes públicos para intervenir en la economía a fin de corregir sus desviaciones más extremas. El Estado social es una respuesta a la necesidad de profundizar en el régimen democrático tras los terribles acontecimientos que asolaron la primera mitad del siglo XX en Europa. Se construye desde el convencimiento de que solo con justicia social es posible la participación de todas y todos en el gobierno del pueblo (BALAGUER CALLEJON, 1992, p. 91).

Las Constituciones Sociales responden a las exigencias de la igualdad sustancial, aquella que repara en la realidad de los hechos y tiene en cuenta la situación de desventaja de algunos colectivos que no pueden acceder a los bienes esenciales. Frente a la igualdad formal del

y social" (COMA, M. B. Constitución y sistema económico. 2. ed. Madrid: Tecnos, 1988. p. 40); Como nos dice Gallego Mendez (apud AGUILA, 2000, p. 20; ARNOLD, 1993, p. 30): "Fue tras el final de la Segunda Guerra Mundial cuando las democracias europeas debieron afirmar una fórmula política-jurídica que evolucionando desde sí misma pudiera adaptarse a las nuevas necesidades del desarrollo técnico, social y económico, impidiendo la caída en el totalitarismo fascista y las posibilidades de revolución y sistema de tipo soviético", "Estado social y crisis del Estado".

16 Sobre los diferentes significados atribuidos a la noción de Estado Social, GONZALEZ MORENO, B. El Estado social: naturaleza jurídica y estructura de los derechos sociales. Madrid: Civitas, 2002, p. 36. En este sentido, FERRAJOLI, L. Derechos y garantías. La Ley del más débil. 2 ed., Madrid: Trotta, 2002, p. 42, entiende que los derechos fundamentales incluyen a los derechos sociales, y "forman el fundamento y el parámetro de la igualdad jurídica y por ello de la que llamaré dimensión 'sustancial' de la democracia, previa a la dimensión política o 'formal' de ésta, fundada en cambio sobre los poderes de la mayoría".

Revista de Direito Econômico e Socioambiental, Curitiba, v. 3, n. 1, p. 169-202, jan./jun. 2012 
constitucionalismo burgués se opone esta otra igualdad que requiere de la intervención de los poderes públicos para corregir la iniquidad de un modelo de desarrollo que llevaba a la exclusión de gran parte de la población, en contraste con la acumulación de riquezas por una oligarquía económica que controlaba también el poder político ${ }^{17}$.

Pero el Estado Social, como es sabido, no constituye una nueva forma de Estado, pues no reniega del que ha sido su modelo, el Estado Liberal, del que asume sus señas de identidad, que en lo que aquí respecta se concretan en la defensa y garantía de la economía de mercado, con la propiedad y la libre iniciativa económica como puntas de lanza del modelo que se quiere defender, al que somete a nuevos principios constitucionales. Por ello es un Estado débil, como afirma Lopez y Lopez, porque "se formula a partir del Estado liberal y con aceptación de muchos de sus postulados"18.

17 En palabras de Garcia-Pelayo (1996, p. 22-23): "El estado social parte de la experiencia de que la sociedad dejada total o parcialmente a sus mecanismos autorreguladores conduce a la pura irracionalidad y que solo la acción del Estado hecha posible por el desarrollo de las técnicas administrativas, económicas de programación de decisiones, etc., puede neutralizar los efectos disfuncionales de un desarrollo económico y social no controlado. Como afirma DE CABO, M. C. La crisis del Estado social. Barcelona: Spanish, 1986, pg. 19: "Surge el denominado Derecho Constitucional económico como conjunto de preceptos que regulan la intervención del Estado en el orden económico y se generaliza la configuración constitucional de los llamados derechos sociales o preceptos que regulan la intervención del Estado en el orden social". Sobre el tema, GARRIDO FALLA, F. El modelo económico en la Constitución Española. Madrid: Instituto de Estudios Económicos, 1981. v. 1. p. 107. Como ha dicho Aparicio Perez, el Estado social surge como producto de un pacto en virtud del cual se produce un cierto desapoderamiento de la capacidad de disposición del propio capital por parte de los empresarios, y se traslada capacidad directa decisoria sobre el proceso productivo y de intercambio al Estado y las organizaciones de trabajadores participan positivamente colaborando con el nuevo proceso, "El Estado social en la jurisprudencia del Tribunal Constitucional”, APARICIO, M. A. El Estado social en la jurisprudencia del Tribunal Constitucional. In: CAMARA VILLAR, G.; CANO BUESO, J. (Ed.). Estudios sobre el Estado social. Madrid: TECNOS, 1993, p. 49-50.

${ }_{18}$ Como se ha dicho, "El principio de Estado social es congenial con una nueva concepción del principio democrático que viene a superar el mito de la voluntad uniforme del pueblo como colectivo homogéneo, acuñado por el constitucionalismo oligárquico para defender los intereses espurios de un determinado grupo social. No fue esta la transformación que protagonizó la burguesía en relación con las formas políticas del antiguo régimen: las abatió a radice. El Estado liberal nace, pues, de una transformación fuerte. De una transformación revolucionaria, por llamar a las cosas por su nombre.

Revista de Direito Econômico e Socioambiental, Curitiba, v. 3, n. 1, p. 169-202, jan./jun. 2012 
Unos nuevos principios constitucionales que ponen en el frontispicio del pacto político la igualdad sustancial ${ }^{19}$, pero que se dota de herramientas jurídicas insuficientes para alcanzar en toda su plenitud la aspiración colectiva de igualdad real. Frente a ella se alzan la propiedad y la libre iniciativa económica, consagradas ahora como derechos fundamentales o garantías institucionales ${ }^{20}$, cuyo contenido esencial se ha de respetar en todo caso. Este contenido esencial se convierte pues en garan-

En cambio el Estado Social es más bien fruto del temor de unos a la revolución y el temor de otros a la dictadura, temores que se intentan conjurar con el encuentro de un punto medio de reformismo de compromiso, de reformismo defensivo para unos, único reformismo posible para a otros", "Estado social y sujeto privado: una reflexión finisecular" Quaderni Fiorentini, 1996, pg. 430. En el mismo sentido, Ferrajoli (2002, p. 42) afirma que el Estado Social se ha desarrollado sin las formas y garantías del Estado de Derecho, solo en la mediación política.

${ }^{19}$ Ahora bien, los instrumentos del Estado Social suponen el paso de la igualdad formal expresada a través de un sujeto único a la igualdad sustancial del sujeto diferenciado. Se pasa, así pues, de un Derecho de la uniformidad, típico del Estado liberal, a un Derecho de la diversidad; de una diversidad muy dispar, que repara en distintos sujetos que se encuentran en situación de debilidad o desventaja social, unos sujetos que se identifican precisamente por unas circunstancias o unas características contingentes, para hacerlos destinatarios de unas políticas específicas que corrijan su situación de desigualdad en el plano material: los consumidores, los enfermos, los menores de edad, las personas mayores, por poner algunos ejemplos; unos sujetos, todos ellos, a los que se les reconoce como atributos jurídicos los derechos sociales, que reflejan el compromiso de los poderes públicos con el disfrute real de unos bienes que se consideran imprescindibles para la realización del principio constitucional básico de la dignidad de la persona. VALPUESTA FERNANDEZ, R. Publicidad registral, seguridad del mercado y Estado social. Anuario de Derecho civil, v. 3, p. 153-190, 2005.

20 Las garantías institucionales son un tipo de protección constitucional que implican el mantenimiento de una institución, sin que pueda ser abolida, ni privada de su función esencial, generalmente también concebida como "contenido esencial", aunque con más amplio poder de configuración por el legislador que con relación a los derechos fundamentales. Ese "contenido esencial" tiene un factor de identificación especialmente potente en el "rostro histórico" (Lange-Kuchinke) de la institución. Su formulación más acabada se encuentra en C. Schmitt, aunque la construcción primigenia, y referida a la propiedad, se encuentra en $\mathrm{M}$. Wolf. Las más típicas desde el punto de vista de la preservación de la existencia de una organización, si se quiere de una Administración, son la autonomía universitaria y la autonomía local; desde el punto de vista de la preservación de un ámbito de poder de los particulares, la propiedad, la libertad de empresa, y el ius nubendi. LOPEZ Y LOPEZ, A. La constitución económica entre derecho público y derecho privado: crónica de una dualidad. Entre la ética, la política y el Derecho. Madrid: Dykinson, 2008. Separata facilitada por el autor, nota 4.

Revista de Direito Econômico e Socioambiental, Curitiba, v. 3, n. 1, p. 169-202, jan./jun. 2012 
tía última de un sistema que se resiste a una trasformación más profunda. Se asegura por esta vía el modelo de economía de mercado, que a lo más se puede someter a limitaciones o restricciones, pero en ningún caso desterrar en el diseño de la sociedad. Por su parte, los instrumentos de intervención de los poderes públicos en las relaciones económicas acusan la debilidad del pacto. En esta línea, los derechos sociales resultan ser de difícil justiciabilidad, siendo así que su desarrollo o implementación se deja en gran medida a la iniciativa de los poderes públicos; incluso, la eficacia horizontal de los derechos fundamentales se reconoce con dificultad por unos sistemas jurídicos que no habían asumido el compromiso de los actores económicos con los valores colectivos recogidos en la Constitución. En otro plano, las políticas de dirección de la economía han tenido un alcance más programático que vinculante; todo ello se refleja también en las restricciones a la actividad económica en defensa de los intereses generales, y en el tratamiento de las nacionalizaciones como instrumentos de intervención estatal en la economía.

Por estas razones se puede afirmar que el desarrollo de los postulados del Estado Social en Europa se debe más al impulso político que a una exigencia jurídica. De ahí que no se hayan generado instrumentos eficaces para asegurar su permanencia (GONZALEZ MORENO, 2002, p. 56 ) ${ }^{21}$.

En este marco, la deriva de la relación entre empresas y Estado está marcada más por los acontecimientos económicos que por la trasformación de un ordenamiento que en su esencia seguía con fidelidad los

${ }^{21}$ Sin embargo, a pesar de sus limitaciones, la formulación en el plano constitucional del Estado Social no está exenta de trascendencia normativa, es decir, de capacidad para conformar el Ordenamiento jurídico. GARRORENA MORALES, A. El Estado español como estado social y democrático de derecho. Madrid: Tecnos, 1984. p. 99. Al efecto se ha resaltado que su potencialidad se despliega en una triple vertiente: como fijación teleológica del Estado, como valor interpretativo del resto del Ordenamiento y como parámetro de constitucionalidad. En otro plano, se ha dicho también que "El principio del Estado social viene a caracterizar la estructura del Ordenamiento y de la constitución, compromete a los órganos del Estado y a los mismos sujetos particulares en una acción de transformación de la sociedad que tiene como últimos fines la igualdad y la extensión del bienestar" CASCAJO CASTRO, J. La tutela constitucional de los derechos sociales. Madrid: CEC, 1988. p. 21. 
postulados del Estado Liberal. Ello obedece en gran medida a que su implementación en el plano jurídico se ha hecho efectiva con instrumentos del Derecho Administrativo, normas de Derecho Público, sin tocar excesivamente la disciplina jurídico privada que regula las relaciones de intercambio, cuyas reglas han permanecido incólumes al cambio político, siendo así que gran parte de la doctrina cultivadora de esta rama del Derecho ha sido ajena a las exigencias de este nuevo constitucionalismo, interpretando sus disposiciones en claves propias del modelo burgués. Solo el Derecho de los consumidores ha irrumpido en este escenario jurídico, como exigencia del Estado Social, pero su capacidad de trasformación ha sido limitada pues se ha visto como un fenómeno menor que en todo caso no toca los basamentos del Derecho patrimonial.

En este contexto el Derecho de la empresa ha tenido la misma deriva, su regulación responde con bastante fidelidad a las exigencias del liberalismo, y sus soluciones se han presentado generalmente como respuestas técnicas a un problema, sin ponderar el conflicto de intereses en claves sociales, pues se ha entendido que esta cuestión no correspondía a una disciplina cuya finalidad debía ser el fortalecimiento de las empresas como actores económicos, independientes del poder político y de los intereses generales (FRIEDMAN, 1962), asumiendo por ello el tradicional concepto de eficiencia de la empresa en términos de maximización y productividad. Y así, se puede comprobar cómo aquéllas en su actividad han sido poco permeables a los valores propios del Estado Social. Solo cuando éstos se han impuesto a través de normas imperativas, se han acomodado a ellos en la medida que la disposiciones se lo exigían y con ese alcance.

Así desde el poder político se han impuesto limitaciones a la actividad empresarial en la defensa de los consumidores, o para preservar el medio ambiente, o incluso se han intervenido los precios de los productos cuando los intereses generales así lo han reclamado, o se ha controlado algunos sectores económicos por su influencia estratégica para la consecución de objetivos sociales, por poner algunos ejemplos de la multiplicidad de actuaciones que los poderes públicos han tenido en el desenvolvimiento de la economía. Pero en todo caso, estas restricciones 
se han visto extrañas al modelo, ajenas a una actividad que debía desenvolverse a impulsos propios, es decir de los intereses empresariales; unas restricciones que, como hemos dicho, se debían soportar siempre que no amenazaran la pervivencia del sistema del que las empresas entienden que son sus señas de identidad.

Sin ánimo de hacer historia, ni de relatar de manera pormenorizada las vicisitudes de las empresas en los Estados europeos, se puede decir que su comportamiento ha respondido, como hemos dicho, más a los acontecimientos económicos que a los impulsos jurídico políticos. Baste como ejemplo, el proceso de privatización y desregulación que desde los años ochenta se ha desarrollado en Europa como respuesta a la crisis económica provocada por la subida del petróleo y por otros hechos que no podemos reproducir. Y como evidencia más contundente podemos citar la situación creada por la actual crisis, en la que las empresas se han impuesto a los Estados hasta el punto de anudar la pervivencia del sistema a la satisfacción de sus intereses, siendo así que la especulación de los dirigentes de las entidades financieras marcan la agenda económica a los gobernantes democráticamente elegidos.

Pero más allá de todo lo expuesto, no se puede negar que en la ciudadanía se ha instalado una cultura ligada a valores sociales, que será la que a la postre se imponga a las empresas sin intermediación de los Estados.

\section{El escenario europeo}

El escenario europeo es si cabe más propicio a las empresas que el que se ha terminado configurando en los ámbitos estatales. El origen económico de la construcción europea ha propiciado que en el marco jurídico que se ha terminado configurando tenga un peso específico el mercado, pues éste fue su origen y aún sigue siendo el soporte principal del proceso de unificación europea.

El fortalecimiento de un mercado interior como respuesta a la internacionalización de las relaciones económicas ha propiciado, sin duda, 
que la producción normativa de las instituciones europeas esté orientada casi en exclusiva a dar seguridad a los intercambios de bienes y servicios en el ámbito regional. De ahí que el peso de estos intereses económicos ligados al fortalecimiento de las empresas sea evidente. Más evidente, si se quiere, por el hecho de que aún se carece de una Constitución que de dimensión política a un proceso de integración y dote a las Instituciones de la Unión de mecanismos de intervención en la economía con fundamento en intereses generales ${ }^{22}$.

En esta línea, los diferentes Tratados que se han sucedido en el proceso de construcción de la Unión Europea han confirmado la libertad de empresa como fundamento de la misma ${ }^{23}$, si bien se ha acordado por el conjunto de los Estados la necesidad de asumir algunos objetivos que sobrepasan la dimensión privada de la actividad económica, y que se han explicitado con más evidencia en el Tratado de Lisboa, estos son el desarrollo sostenible, la protección del medio ambiente ${ }^{24}$ y la protección

${ }^{22}$ El art. 3 de la Versión Consolidada del Tratado de Funcionamiento de la Unión Europea establece como competencias exclusivas de la Unión: "La Unión dispondrá de competencia exclusiva en los ámbitos siguientes: a) la unión aduanera; b) el establecimiento de las normas sobre competencia necesarias para el funcionamiento del mercado interior; c) la política monetaria de los Estados miembros cuya moneda es el euro; d) la conservación de los recursos biológicos marinos dentro de la política pesquera común; e) la política comercial común".

${ }^{23}$ Art. 120 de la Versión Consolidada del Tratado de Funcionamiento de la Unión Europea: "Los Estados miembros llevarán a cabo sus políticas económicas con vistas a contribuir a la realización de los objetivos de la Unión, definidos en el artículo 3 del Tratado de la Unión Europea, y en el marco de las orientaciones generales contempladas en el apartado 2 del artículo 121. Los Estados miembros y la Unión actuarán respetando el principio de una economía de mercado abierta y de libre competencia, favoreciendo una eficiente asignación de recursos y de conformidad con los principios enunciados en el artículo 119".

${ }^{24}$ El art. 3 de la Versión Consolidada del Tratado de la Unión Europea dispone: "3. La Unión establecerá un mercado interior. Obrará en pro del desarrollo sostenible de Europa basado en un crecimiento económico equilibrado y en la estabilidad de los precios, en una economía social de mercado altamente competitiva, tendente al pleno empleo y al progreso social, y en un nivel elevado de protección y mejora de la calidad del medio ambiente. Asimismo, promoverá el progreso científico y técnico".

Revista de Direito Econômico e Socioambiental, Curitiba, v. 3, n. 1, p. 169-202, jan./jun. 2012 
del consumidor ${ }^{25}$. Aunque no se puede olvidar la dimensión social de las normas laborales y la prohibición de discriminar, con especial mención a la igualdad de mujeres y hombres, muy presente en el texto.

En todo caso no se puede negar la indudable influencia que tienen las empresas en la política que desarrollan las instituciones europeas. Buena prueba de ello es la razón que impulsa el importante desarrollo de los derechos de los consumidores, cuya justificación reside en la necesidad de fortalecer el mercado interior, que requiere articular un mismo nivel de protección de los adquirentes de bienes y servicios con independencia del país en el que residan, con el claro propósito de generar confianza en la contratación trasnacional en el seno del espacio europeo ${ }^{26}$. Y buena prueba de lo anterior es sin duda la dimensión que tiene la defensa de la competencia en la organización del mercado. Con una fe casi ciega en sus bondades para el progreso económico se ha impuesto incluso a las políticas intervencionistas de los Estados, vetando la protección a determinadas actividades cuyo mantenimiento exigen los intereses sociales; hasta el punto de que se ha convertido en el gran eje vertebrador de una política económica que intenta escapar a los límites, si bien débiles, del Estado Social. Se ha producido pues una estrecha correlación del mercado y la defensa de la competencia, como esquemas de racionalización y organización del sistema económico.

De todo lo anterior da buena cuenta también el proceso de unificación del Derecho privado en la UE, que ha pasado a ser un asunto de los académicos, actúen éstos por iniciativa propia o a instancia de las instituciones comunitarias. Y así, se está redactando un conjunto normativo del

${ }^{25}$ Art. 169 de la Versión Consolidada del Tratado de Funcionamiento de la Unión Europea: "1. Para promover los intereses de los consumidores y garantizarles un alto nivel de protección, la Unión contribuirá a proteger la salud, la seguridad y los intereses económicos de los consumidores, así como a promover su derecho a la información, a la educación y a organizarse para salvaguardar sus intereses".

${ }^{26}$ Sobre la política de protección de los consumidores desarrollada en el seno comunitario, vid., JOUSTRA, C. Consumer Law. In: HARTKAMP, A. M. et al. Towards a european civil code, towards a european civil code. 3rd ed. Hague: Ars Aequi Libri; London: Nijmegen; Boston: Kluwer International, 2004. p. 143-146.

Revista de Direito Econômico e Socioambiental, Curitiba, v. 3, n. 1, p. 169-202, jan./jun. 2012 
mercado sin referencia constitucional, y en gran medida al margen de las requisitorias constitucionales de los distintos Estados (INFANTE RUIZ, 2008, p. 1-44). Los cultivadores de un Derecho, que surgió bajo los auspicios de las Constituciones liberales y que a duras penas se han amoldado a las directrices del Estado social, son los que están articulando un conjunto de normas que nos presentan como neutrales y técnicas, pero que no son más que la expresión de la racionalidad de un mercado que se desenvuelve a impulsos propios porque el poder político así lo ha querido ${ }^{27}$.

En este contexto, el poder de las empresas, como se ha dicho, es evidente, y su libertad de desenvolvimiento se escapa en gran medida al conjunto de la ciudadanía. Sin embargo, se debe reparar en un fenómeno que puede resultar de interés para el tema que abordamos. Nos referimos a la asunción por la ciudadanía de los valores implícitos en el Estado Social, de forma que ello se ha incorporado al imaginario colectivo sobre el modelo de sociedad a la que aspiran. Su dimensión es más cultural que jurídica, por las razones que hemos expuesto, pero no cabe duda que transciende a la relación con las empresas e impregna las aspiraciones que sobre ellas se tienen.

\section{El escenario internacional}

En este escenario es aún más evidente la falta de control de las empresas que se desenvuelven a impulsos propios, imponiendo sus intereses, y sorteando las limitaciones a las que las puedan someter los distintos Estados, a pesar de los intentos por regular su actividad en el plano

27 Por ello, en Europa ha irrumpido con mucha fuerza el debate en torno a la necesidad de introducir lo que se ha convenido en llamar "justicia social" en la construcción del Derecho contractual europeo, especialmente a raíz de la publicación de un manifiesto firmado por prominentes nombres de la doctrina jurídica europea reunidos en torno al STUDY GROUP ON SOCIAL JUSTICE IN EUROPEAN PRIVATE LAW. Social Justice in European Contract Law: a Manifesto. European Law Journal, v. 10, n. 6, p. 653-674, 2004. Este manifiesto ha sido firmado y apoyado por juristas como Ugo Mattei, Horatio Muir Watt, Hugh Collins, Mauro Bussani, Guido Alpa, Martijn Hesselink, Brigitta Lurger o Stefan Grundmann, por citar a algunos de los más conocidos.

Revista de Direito Econômico e Socioambiental, Curitiba, v. 3, n. 1, p. 169-202, jan./jun. 2012 
internacional ${ }^{28}$. Pocos ejemplos hay que poner para evidenciar una realidad que todas y todos conocemos. Baste únicamente mencionar la crisis económica para poner de relieve cómo la falta de control por parte del Estado de empresas de los EEUU ha permitido unas prácticas mercantiles espurias que han contaminado las economías regionales y Estatales, sin que al día de hoy se haya impuesto un poder político que encauce la actividad de las entidades financieras hacia la defensa de los intereses de la ciudadanía.

Sin embargo, no se puede afirmar que estas empresas funcionan sin normas pues, como hemos dicho, las empresas necesitan el Derecho, si bien sea el suyo, para preservar sus beneficios al margen de cualquier preocupación colectiva. Un Derecho que se está creando a medida de sus intereses en instancias internacionales. Hacemos referencia a la Uncitral que opera en el seno de NNUU, o a la OMC. De tal modo que está surgiendo un nuevo ius mercatorum al margen de los Estados o, mejor dicho, con la connivencia de los Estados que se perciben incompetentes para controlar el poder de unas empresas que actúan al margen de los mismos (MARRELLA, 2003).

En otro plano se debe resaltar cómo a impulsos de los movimientos sociales y de la opinión pública en general se ha elaborado un cuerpo normativo que recoge los que se consideran valores universales, nos referimos a los diferentes Tratados que reconocen y desarrollan los $\mathrm{DDHH}$, también a los acuerdos internacionales sobre la defensa del medio ambiente, de tal manera que al mismo tiempo que se cristaliza un Derecho de empresa ajustado a los objetivos de la misma, se desarrolla

28 Después de la Conferencia de Baudung (1955), en la que el movimiento de los no alineados emergió, estos países del Tercer Mundo hicieron demandas precisas en relación con un nuevo orden internacional y económico. Propusieron reformas estructurales en el orden de comercio mundial, en comunicaciones, en el acceso a nuevas tecnologías... y, en el primer caso, un control público de las empresas multinacionales. Estas demandas se hicieron muy populares en los años 60s: se iniciaron negociaciones entre los países industrializados y los del Tercer Mundo, bajo los auspicios de la CNUCD. La Asamblea General de Naciones Unidas decidió crear una comisión de Multinacionales así como un centro de investigación sobre sus actividades. El propósito fue ciertamente desarrollar un instrumento universal para sujetar a las multinacionales a reglas públicas (FONTENEAU, 2003).

Revista de Direito Econômico e Socioambiental, Curitiba, v. 3, n. 1, p. 169-202, jan./jun. 2012 
este otro Derecho que tiene mucho que ver con la dignidad humana en todas sus manifestaciones, y la protección de bienes esenciales para la humanidad. No obstante, ambos derechos se desenvuelven en planos diferentes pues se carece de instituciones internacionales que puedan imponer el respeto a los derechos humanos a unas empresas que se desenvuelven con muy pocas trabas.

Y en este sentido es evidente que más allá de las Convenciones, se ha generado una opinión pública comprometida con la defensa de los DDHH y la protección del medio ambiente. Una opinión pública muy activa con capacidad de influir en los comportamientos de los ciudadanos en su relación con las empresas. Ello se debe a la acción de los movimientos sociales y al activismo de las ONGs, que han llamado la atención acerca la importancia de estos valores, denunciando las prácticas de gobiernos y empresas que los vulneran. En este punto también conviene resaltar el papel que desempeñan los medios de comunicación en la difusión de las ideas, los hechos o los acontecimientos que contribuyen sin duda a conformar una cierta conciencia colectiva de la necesidad de exigir a las empresas un mayor compromiso con los valores colectivos.

\section{Conclusión}

En este recorrido hemos podido comprobar las dificultades con las que se ha encontrado el poder político para involucrar a las empresas en la realización de los principios y valores con dimensión social, es decir, aquellos que tienden a la realización de la igualdad sustancial y la justicia social. Las empresas se han mantenido ajenas a los mismos por entender que son incompatibles con sus propios fines, que se concretan en la maximilación de ganancias y en la productividad. Una dificultad que es más evidente en aquellos ámbitos en los que existe una mayor debilidad institucional para actuar en el mercado. Ello ocurre a nivel regional, dado la dimensión económica que aún tienen los procesos de integración, pero es aún más cierto en 
el escenario internacional, en el que se carece de mecanismos o de instrumentos eficaces para intervenir en la actividad empresarial.

Sin embargo, como hemos señalado, estos valores y principios, a los que hacemos referencia, tienen una gran influencia en el conjunto de la población. En efecto, cada vez y en mayor medida integran las aspiraciones colectivas, hasta el punto de influir en las decisiones que las personas adoptan en su relación con los poderes públicos y con los actores sociales y, muy especialmente, económicos. Y así, podemos comprobar cómo la difusión de que una empresa recurre al trabajo infantil, o que su actividad es altamente contaminante puede retraer a los consumidores o a los que invierten en bolsa, por poner algunos ejemplos, a adquirir sus productos, influyendo en consecuencia en la cuenta de resultado de las empresas involucradas.

Sin embargo, entendemos que ante estas demandas la respuesta no debe ser la responsabilidad social corporativa o, al menos, no debe ser la solución principal, por varias razones. En primer lugar porque pone de manifiesto el fracaso de los poderes públicos para imponer a las empresas objetivos ligados a los valores del Estado Social. Lo dicho se manifiesta con mayor contundencia en los espacios regionales por su debilidad institucional. Y es clamoroso en el ámbito internacional en el que es más evidente la falta de control de las empresas. En definitiva, lo que se conoce como responsabilidad social corporativa no es más que un nuevo intento de someter la actividad económica a las exigencias de los DDHH o de la economía sostenible y del respeto al medio ambiente ${ }^{29}$.

29 Problema lo pone de manifiesto el Libro Verde sobre la Responsabilidad Social de las Empresas: no obstante, la responsabilidad social de las empresas no se debe considerar sustitutiva de la reglamentación o legislación sobre derechos sociales o normas medioambientales, ni permite tampoco soslayar la elaboración de nuevas normas apropiadas. En los países que carecen de tales reglamentaciones, los esfuerzos se deberían centrar en la instauración del marco legislativo o reglamentario adecuado a fin de definir un entorno uniforme a partir del cual desarrollar prácticas socialmente responsables. LIBRO VERDE para fomentar un marco europeo para la responsabilidad social de las empresas. Bruselas, 18.7.2001, $\operatorname{COM(2001),~par.~2.~22.~En~este~sentido,~cabe~citar~el~}$ Proyecto de Ley de Responsabilidad Social Empresarial impulsado por la Junta de Extremadura.

Revista de Direito Econômico e Socioambiental, Curitiba, v. 3, n. 1, p. 169-202, jan./jun. 2012 
Y este sometimiento de las empresas a los valores antes referidos no se implementa con la intermediación de los Estados o los poderes públicos que representan al conjunto de la ciudadanía, sino por la presión de los denominados stakeholders que son, como hemos dicho, los operadores o grupos de interés con capacidad de influir en el comportamiento de las empresas. Ello significa que el cumplimiento de normas tan elementales, como las expuestas al principio, se deja a la iniciativa de éstos, cuyo comportamiento puede estar mediatizado por un conjunto de circunstancias que se nos escapan, y que poco tienen que ver con el compromiso de los valores colectivos definidos por la comunidad.

Y finalmente, son razones económicas de rentabilidad empresarial las que han acercado a las empresas a este tipo de preocupaciones que hemos relatado, por lo que estas mismas razones económicas pueden aconsejar otro tipo de comportamiento empresarial cuando la rentabilidad así lo requiera, como puede ocurrir en la actual crisis del mercado ${ }^{30}$.

30 1. Debilitar o incluso abolir el derecho a legislar y establecer contratos, al reemplazarlos por instrumentos no obligatorios sin ningún valor legal (desregulación-nivel-cero). 2. Debilitar o incluso abolir el papel regulador y arbitral de las autoridades públicas nacionales e internacionales, al reemplazarlas por regulaciones voluntarias y parciales de las empresas. 3. Afectar aún más a las autoridades públicas nacionales e internacionales (OIT, Consejo de Europa) en su papel como supervisores de la aplicación de los sistemas de fijación de normas, al reemplazarlos por organismos privados. 4. Ampliar la esfera del derecho privado en detrimento del derecho público: instrumentos privados (códigos de conducta, etiquetas, estatutos) controlados por organismos privados de acuerdo a sus propias regulaciones... en lugar de gestión pública e inspección laboral. Esto es claramente una inversión de la democracia: las empresas privadas pretenden saber y garantizar el interés común en lugar de las autoridades nacionales e internacionales. 5. Escoger a sus socios. Esta estrategia pretende ofrecer asociaciones a varios actores (partes interesadas: ONGs, derechos humanos, consumidores, organizaciones de desarrollo, ambientales...) en nombre de la naturaleza multidimensional de los problemas. 6. Además del hecho de que el nuevo instrumento quiere sustituir a los acuerdos colectivos, las muchas partes interesadas se hacen competidores más dóciles y más flexibles que los sindicatos y, gradualmente, estos nuevos actores, sustituirán a los sindicatos quienes han ganado, en una lucha que duró más de un siglo, la representación colectiva de los trabajadores así como el reconocimiento legal de los contratos colectivos. De esta forma, las empresas pueden escoger a los socios que les convengan y hacer a un lado a los otros (FONTENEAU, 2003).

Revista de Direito Econômico e Socioambiental, Curitiba, v. 3, n. 1, p. 169-202, jan./jun. 2012 


\section{Referencias}

AGUILA, R. Del. (Ed.). Manual de ciencia política. 2. ed. Madrid: Marcial Pons, 2000.

APARICIO, M. A. El Estado social en la jurisprudencia del Tribunal Constitucional. In: CAMARA VILLAR, G.; CANO BUESO, J. (Ed.). Estudios sobre el Estado social. Madrid: TECNOS, 1993. p. 49-61.

ARNOLD, R. Bases dogmáticas del principio del estado social en el derecho constitucional alemán. In: CAMARA VILLAR, G.; CANO BUESO, J. (Ed.). Estudios sobre el Estado social. Madrid: Tecnos, 1993. p. 30-40.

BALAgUer CALlEJON, F. Derecho y mercado. Revista de Derecho Patrimonial, n. 3, p. 21-26, 1999.

BALAGUER CALLEJON, F. Fuentes de derecho. Madrid: Tecnos, 1992.

BIGNÉ, E. Percepción de la responsabilidad social corporativa: un análisis crosscultural. Universia Business Review-Actualidad Económica, n. 5, p. 14-27, primer trimestre, 2005.

CARRANCHO HERRERO, M. T. El problema del ejercicio de actividades económicas por las fundaciones. Revista Derecho Privado, p. 94-117, febrero, 1991. CASCAJO CASTRO, J. La tutela constitucional de los derechos sociales. Madrid: CEC, 1988.

COMA, M. B. Constitución y sistema económico. 2. ed. Madrid: Tecnos, 1988. CONFERÊNCIA de Bandung. 1955. Disponível em: <http://www.diario-universal. com/2007/04/aconteceu/conferencia-de-bandung/>. Acesso em: 24 dez. 2011.

CORTÉS GARCÍA, F. J. Ética empresarial y responsabilidad social corporativa. Boletín Económico de ICE, n. 2936, p. 40-48, 2008. 
CUERVO, A. Eficiencia y responsabilidad social corporativa. In: AA.VV. Amicorum: Economía, empresa y trabajo: homenaje a Manuel Alonso Olea. Madrid: Civitas, 2003. p. 89-101.

CUESTA GONZALEZ, M. El porqué de la responsabilidad social corporativa. Boletín Económico de ICE, n. 2813, p. 48-51, 2004.

DE CABO M. C. La crisis del Estado social. Barcelona: Spanish, 1986.

EMBID IRUJO, J. M. La responsabilidad social corporativa ante el derecho mercantil. Cuadernos de derecho y comercio, n. 42, p. 11-44, 2004.

ESTEBAN DE LA ROSA, F. La protección de los consumidores en el mercado interior europeo. Granada: Comares, 2003.

FERRAJOLI, L. Derechos y garantías. La ley del más débil. 2. ed. Madrid: Trotta, 2002.

FONT GALÁN, J. I. La empresa en el Derecho mercantil. In: JIMÉNEZ SÁNCHEZ, G. J. Derecho mercantil I. 11. ed. Barcelona: Ariel, 2007. p. 59-64.

FONTENEAU, G. Responsabilidad social corporativa: previendo sus implicaciones sociales. 2003. Disponível em: <http://www.jussemper.org/Inicio/Resources/RSCimplicacionessoc.pdf $\rangle$. Acesso em: 29 dez. 2011.

FRIEDMAN, M. Capitalism and freedom. Chicago: University of Chicago Press, 1962.

FUENTES GANZO, E. La responsabilidad social corporativa. Su dimensión normativa: implicaciones para las empresas españolas. Pecvinia, n. 3, p. 1-20, 2006.

FUNDACIÓN ENTORNO-BCSD ESPAÑA. Consejo regional español del WBCSD. Disponível em: <http://www.fundacionentorno.org/Fundacion/Consejo, Regional,Espanol,WBCSD,179.htm >. Acesso em: 29 dez. 2011.

GARCIA-PELAYO, M. Las transformaciones del Estado contemporáneo. Madrid: Alianza, 1996. 
GARRIDO FALLA, F. El modelo económico en la Constitución española. Madrid: Instituto de Estudios Económicos, 1981. v. 1.

GARRORENA MORALES, A. El Estado español como Estado social y democrático de derecho. Madrid: Tecnos, 1984.

GONZALEZ MORENO, B. El Estado social: naturaleza jurídica y estructura de los derechos sociales. Madrid: Civitas, 2002.

HÄBERLE, P. Incursus: perspectiva de una doctrina constitucional del mercado. Pensamiento constitucional, v. 4, n. 4, p. 13-29, 1997.

INFANTE RUIZ, F. J. Entre lo político y lo académico: un Common Frame of Reference de derecho privado europeo. InDret, n. 2, p. 1-44, 2008.

JOUSTRA, C. Consumer Law. In: HARTKAMP, A. M. et al. Towards a european civil code, towards a european civil code. $3 r d$ ed. Hague: Ars Aequi Libri; London: Nijmegen; Boston: Kluwer International, 2004. p. 143-146.

LOPEZ Y LOPEZ, A. La constitución económica entre derecho público y derecho privado: crónica de una dualidad. Entre la ética, la política y el derecho. Madrid: Dykinson, 2008.

MARRELLA, F. La nuova lex mercatoria: Principi Unidroit ed usi dei contratti del commercio Internazionale. Milano: CEDAM, 2003.

MENDEZ PICAZO, M. T. Ética y responsabilidad social corporativa. ICE, Ética y Economía, n. 823, p. 141-150, 2003.

PAZ-ARES, C. Economía política como jurisprudencia racional. Anuario de Derecho Civil, v. 24, n. 3, p. 601-708, 1981.

PEREZ, J. L. M.; NAVARRETE, C.; VIDA, M. N. M. (Ed.). Comentario a la Constitución socio-económica de España. Granada: Comares, 2002.

RITTER, G. A. Comienzos y el desarrollo del Estado Social en Alemania, Europa y los Estados Unidos hasta la $2^{a}$ Guerra Mundial. Studia Historica. Historia contemporánea, n. 8, p. 157-170, 1990. 
SAN MIGUEL, L. G. (Ed.). El principio de igualdad. Madrid: Dykinson, 2000. STUDY GROUP ON SOCIAL JUSTICE IN EUROPEAN PRIVATE LAW. Social Justice in European Contract Law: a Manifesto. European Law Journal, v. 10, n. 6, p. 653-674, 2004.

VALPUESTA FERNANDEZ, R. Publicidad registral, seguridad del mercado y Estado social. Anuario de Derecho civil, v. 3, p. 153-190, 2005.

Recibido: 31/10/2011

Recebido: 31/10/2011

Aprobado: 13/07/2012

Aprovado: 13/07/2012 